\section{Science in Central Europe}

SIR - The views presented in your coverage of science in Central Europe (Nature $372,591 ; 1994)$ are not only of general interest but could also be very helpful for scientists and political decision-makers in the Czech Republic.

But the most serious problem for Czech science in my opinion is the lack of any consistent scientific policy.

As you mentioned, as a member of the Czech parliament, I formally asked the Prime Minister, Václav Klaus, why the government had procrastinated for more than two years about the results of a report on the Prague Institute of Advanced Studies (PIAS) prepared at the request of our government and funded by PHARE, thus wasting the financial resources of the European Commission. This is especially important because this document contains valuable recommendations on science policy. The answer was that the Czech Republic has no formal obligation to use the results of such a study, and that the government is already preparing plans for the future development of Czech science and technology.

This is an interesting contrast to the answer to my parliamentary question at the end of 1992. I asked then if the government had or was preparing any policy for science and technology. The same prime minister told me that the government was working on the project and that it should be completed before June 1993.

The disappearance of the centralized economic system makes it important to re-define the role of scientific and technological institutes, including universities and the academies of science. We must also set up new sources of funding and build support for disciplines and technologies that were undervalued in the past but which are vital for progress. Closer cooperation is needed between both our republic and other Central and Eastern European countries with other European countries.

With this in mind, the Committee of Science and Technology of the Council of Europe has organized a conference on "Scientific and technological cooperation with the Central and East European countries" to be held on 5 to 7 June 1995 in Prague. This will address how science and technology can be reformed in the Czech Republic, and will appeal to the government to help solve the problems. Topics to be covered include the comparative importance of basic and applied research; the reforms required for creating a national capacity for technological innovation; the temporary or permanent loss of major intellectual and scientific resources; a critical overview of international programmes such as PHARE, TACIS, PELO-

Charles University,
COPERNICUS; and the integration of Central and East European countries into established European organizations (such as CERN, ESA and EUREKA).

Marie Stiborová

Department of Biochemistry,

Prague, Czech Republic

SIR - I would like to correct what you say about Czech universities, and particularly about Charles University (Nature 372, 602 ; 1994).

It is true that Charles University has changed the rules for the award of docentships and professorships but it has done so in a spirit quite different from that presented in the article. We have raised the requirements for both research and instruction. The statement that only candidates with teaching experience at Charles University may apply for professorships is untrue. Candidates can fulfil their teaching obligations at any university in either the Czech Republic or abroad. Karel Malý

(Rector)

Charles University,

11636 Prague 1, Czech Republic

\section{Vogt defended}

SIR - In November 1994, the US National Science Board voted to support LIGO (the Laser Interferometer Gravitationalwave Observatory), a project of enormous technical difficulty and vast scientific promise, in spite of increases in both budget and time scale relative to earlier estimates.

In an article on this important decision (Nature 372, 311; 1994), you reported that unnamed sources blamed the increases solely on the 'management failures' of Rochus (Robbie) Vogt, LIGO's first director. Although it is convenient to assign all increases to one simple reason, the actual situation is far more complex. The National Science Foundation, Caltech and LIGO management, in various measures, contributed to the increases. Some of this is hinted at in the cost increase breakdown given in the same article. The details of both the original time and cost estimate and the new one are matters of public record.

Some day, when the history of gravity wave exploration of the Universe is written, Vogt, together with Drever, Weiss and Thorne, will be counted among its most influential early participants. Vogt took hold of LIGO when its future was highly uncertain, and by the force of his personality, energy, vision and leadership brought it to the threshold of construction. He was the right person, in the right place, at the right time. If, at this point in the project's evolution, another leader with other talents is needed, that in no way reflects poorly on what Vogt has accomplished. All of this has evolved in the best tradition of responsible scientific and fiscal decision. No scapegoats are needed.

Charles W. Peck

Division of Physics, Mathematics, and Astronomy,

California Institute of Technology,

Pasadena, California 91125, USA

\section{But is it science?}

SIR - John Maddox's final question posed in his discussion of the debate between Stuart Kauffman and John Maynard Smith about Kauffman's evolutionary scenarios (Nature 373, 555; 1995) should be made even more specific. Maddox asks: "Can a model be heuristically valuable even when it entails only a sketchy correspondence with the real world?" Given the universal concern of evolutionary biologists with the actual principles and historical details of evolution on the planet Earth, one needs to ask of the Kauffman ideas how well they correspond to: (1) what is known about pre-biotic conditions on Earth and (2) what we know about actual mechanisms of biological development. The correspondence is, I believe, quite weak in both areas.

The use of scientific ideas to construct hypothetical worlds is, of course, an honourable intellectual pursuit but it is not science. It is science fiction.

Adam S. Wilkins

BioEssays,

Company of Biologists Ltd,

Austin Building, Pembroke Street,

Cambridge CB2 2ED, UK

\section{Taxol trademark}

SIR - I support your view on "Names for hi-jacking"1. Taxol has been widely used as a trivial name since its first characterization in $1971^{2}$. Taxol is derived from the generic name Taxine tracing back to $1856^{3}$ which I have discussed in a review ${ }^{4}$. Bristol-Myers and an Indian company that is using 'taxol' as a trade mark should stop doing so.

In principle, no chemical name should be misappropriated as trademark.

Nizam U. Khan

Department of Chemistry,

Aligarh Muslim University,

Aligarh 202002, UP,

India

1. Nature 373, 370 (1995).

2. Wani, M. C. et al. J. Am. chem. Soc. 93, 2325-2327 (1971).

3. Lucas, H. Arch. Pharm. 95, 145 (1856)

4. Khan, N. U. \& Parveen, N. J. scient. ind. Res. 46, 512-516 (1987)

NATURE · VOL $374 \cdot 30$ MARCH 1995 